\title{
Mouse Pathology Shared Resource
}

National Cancer Institute

\section{Source}

National Cancer Institute. Mouse Pathology Shared Resource. NCI Thesaurus. Code C39463.

The Mouse Pathology Shared Resource provides histologic and hematopoietic research support services to Cancer Center investigators and others studying the pathogenesis and treatment of organ and hematologic malignancies in mouse models of human cancer. 